\title{
Effect of Surface Modification of Palygorskite on the Properties of Polypropylene/Polypropylene-g-Maleic Anhydride/Palygorskite Nanocomposites
}

\author{
David Cisneros-Rosado and Jorge Alonso Uribe-Calderon \\ Centro de Investigación Científica de Yucatán, A.C., Unidad de Materiales, Calle 43 No. $130 \times 32$ y 34, \\ Colonia Chuburná de Hidalgo, 97205 Mérida, YUC, Mexico
}

Correspondence should be addressed to Jorge Alonso Uribe-Calderon; jorge.uribe@cicy.mx

Received 22 February 2017; Revised 12 May 2017; Accepted 4 June 2017; Published 19 July 2017

Academic Editor: Domenico Acierno

Copyright (C) 2017 David Cisneros-Rosado and Jorge Alonso Uribe-Calderon. This is an open access article distributed under the Creative Commons Attribution License, which permits unrestricted use, distribution, and reproduction in any medium, provided the original work is properly cited.

The effect of surface modification of palygorskite $(\mathrm{Pal})$ on filler dispersion and on the mechanical and thermal properties of polypropylene (PP)/polypropylene grafted maleic anhydride (PP-g-MAH)/palygorskite (Pal) nanocomposites was evaluated. A natural Pal mineral was purified and individually surface modified with hexadecyl tributyl phosphonium bromide and (3Aminopropyl)trimethoxysilane; the pristine and modified Pals were melt-compounded with PP to produce nanocomposites using PP-g-MAH as compatibilizer. The grafting of Pal surface was verified by FT-IR and the change in surface hydrophilicity was estimated by the contact angle of sessile drops of ethylene glycol on Pal tablets. The extent of Pal dispersion and the degree of improvement in both the mechanical and thermal properties were related to the surface treatment of Pal. Modified Pals were better dispersed during melt processing and improved Young's modulus and strength; however, maximum deformation tended to decrease. The thermal stability of PP/PP-g-MAH/Pal nanocomposites was considerably improved with the content of modified Pals. The degree of crystallinity increased with Pal content, regardless of the surface modification. Surfactant modified Pal exhibited better results in comparison with silane Pal; it is possible that longer alkyl chains from surfactant molecules promoted interactions with polymer chains, thereby improving nanofiller dispersion and enhancing the properties.

\section{Introduction}

Palygorskite (Pal) is a type of clay with a unique threedimensional structure and fibrous morphology, exhibiting chemical and thermal stability, high aspect ratio, large specific surface area $\left(150-200 \mathrm{~m}^{2} / \mathrm{g}\right)$, and mechanical strength $[1,2]$.

The chemical formula for palygorskite is reported as $\left[(\mathrm{Mg}, \mathrm{Al}, \mathrm{Fe})_{5} \mathrm{Si}_{8} \mathrm{O}_{20}(\mathrm{OH})_{2}\left(\mathrm{OH}_{2}\right)_{4}\right] \cdot 4 \mathrm{H}_{2} \mathrm{O}$ [3]; the clay structure is composed of octahedral and tetrahedral units of silicates that form interconnected channels with dimensions of $3.7 \times 10.6 \AA$. Substitutions of $\mathrm{Si}$ for $\mathrm{Al}$ atoms in the tetrahedral units provide to clay a cation exchange capacity (CEC) ranging from 20 to $30 \mathrm{meq} / 100 \mathrm{~g}$ [2]. These interesting properties suggest that $\mathrm{Pal}$ can be used as polymer nanofiller [4], although it is mainly employed as a catalyst carrier [5-7] or as adsorbent material $[8,9]$.
The hydrophilic nature of Pal could represent a challenge for the production of polymer/Pal nanocomposites. A recurrent procedure to promote $\mathrm{Pal}$ dispersion within the polymer is to modify its surface with organic modifiers in order to reduce the interactions among silicate fibers and to promote compatibility with the polymer matrix. Pal has been traditionally modified with a silane coupling agent $[1,10-$ 13] to produce polymer/Pal nanocomposites based on epoxy resin [3], Nylon 6 [14-17], natural rubber [18], ethylenevinyl acetate copolymers [19], or poly-aniline [20]. However, the use of cationic surfactants to modify Pal has been less frequently reported [21-25].

On the other hand, PP is one of the most widely used polyolefins due to its low cost, low density, and extraordinary versatility in terms of applications and recycling [26]. Several studies have been devoted to improving the mechanical 
[27-30] and thermal properties of PP [31] by incorporating mineral fillers (i.e., clay) in an effort to diversify the use of PP. The intrinsic nonpolar nature of PP makes it incompatible with clay fillers; the use of modified clays and compatibilizers (such as polypropylene grafted maleic anhydride [32-34]) is a common approach to produce $\mathrm{PP} /$ clay nanocomposites. A number of studies have focused on the preparation of PP/PP-g-MAH/Pal nanocomposites [35-38], but despite these efforts, the factors promoting the dispersion of $\mathrm{Pal}$ and improvement of the properties are not yet completely understood.

In this study, the effect of surface modification of Pal on nanofiller dispersion and the enhancement of properties was evaluated on polypropylene (PP) nanocomposites prepared by melt compounding using polypropylene grafted maleic anhydride (PP-g-MAH) as compatibilizer. Thus, a Pal mineral was purified and characterized and separately modified with a conventional silane coupling agent (3Aminopropyl)trimethoxysilane (APTMS) and a cationic surfactant (hexadecyl tributyl phosphonium bromide, HDTBP) to produce Pals with different surface energies. To the best of our knowledge, there are no previous reports concerning Pal modification with HDTBP to produce polymer nanofiller. It was expected that surface modification promotes the deagglomeration of silicate fibers, thereby improving dispersion during melt compounding and enhancing some properties. Pal characterization involved Scanning Electron Microscopy (SEM) and Fourier Transform Infrared Spectroscopy (FTIR); Pal dispersion within PP was determined by SEM and TEM; the mechanical and thermal properties (Thermogravimetric Analysis, TGA and Differential Scanning Calorimetry (DSC)) of the resulting nanocomposites were also determined.

\section{Experimental}

2.1. Materials. Palygorskite mineral was directly collected from a seam in Chapab, Mexico. Pal was purified with hydrochloric acid (J. T. Baker, 37\% w/v). Ethylene glycol from Sigma-Aldrich was used to determine the surface energy of modified Pal. Isotactic PP (Valtec HP423M, melt flow index of $3.8 \mathrm{~g} / 10 \mathrm{~min}, \mathrm{Mw}=232,400 \mathrm{~g} / \mathrm{mole}$, and density of $0.9 \mathrm{~g} / \mathrm{cm}^{3}$ ) was used as a matrix, and PP-g-MAH of Eastman G Polymers $^{\mathrm{TM}}$ (Eastman G-3015, maleic anhydride 1.32 wt.\%, acid number of $15 \mathrm{mg} \mathrm{KOH} / \mathrm{g}$, and $\mathrm{Mw}=47,000 \mathrm{~g} / \mathrm{mole}$ ) was used as compatibilizer. (3-Aminopropyl)trimethoxysilane (APTMS 99\% purity) from Sigma-Aldrich and hexadecyl tributyl phosphonium bromide $\mathrm{HDTBP}^{+} \mathrm{Br}^{-}, 98 \%$ purity) from Alpha Aesar were used to modify the Pal surface.

2.2. Clay Purification. Pal mineral (100 g), as received, was dispersed mechanically with $3 \mathrm{~L}$ of distilled water for $1 \mathrm{~h}$. Subsequently, the slurry was filtered through a 70 mesh sieve $(0.224 \mu \mathrm{m}$, standard ASTM E 11-70) and $100 \mathrm{~mL}$ of hydrochloric acid solution $(1 \mathrm{~N})$ was added to the Pal slurry and stirred mechanically for $1 \mathrm{~h}$. Several cycles of washing/centrifuge were carried out until a $\mathrm{pH} \sim 7$ was achieved [39]. Finally, the purified Pal (Pal-1) was dried in a convection oven at $100^{\circ} \mathrm{C}$ for $24 \mathrm{~h}$. A cation exchange capacity of $26.2 \mathrm{meq} / 100 \mathrm{~g}$ was determined for Pal, following the procedure reported in the literature [40].

2.3. Pal Modification with Silane Coupling Agent. Conventional silane modification was performed on Pal-1 [8]: $10 \mathrm{~g}$ of Pal-1 was dispersed with $170 \mathrm{~mL}$ of toluene using an ultrasonic bath $(10 \mathrm{~min})$ and then it was filtered through a 70 mesh sieve. APTMS was added dropwise to the mixture (under vigorous mechanical stirring) at the ratio Pal: silane of $1: 1 \mathrm{~g}: \mathrm{ml}$. The reaction was conducted under reflux for $2 \mathrm{~h}$ at $45^{\circ} \mathrm{C}$ under mechanical stirring. The resulting modified $\mathrm{Pal}$ was washed with toluene and anhydrous ethanol to remove unreacted silane coupling agent. Finally, the silane modified $\mathrm{Pal}(\mathrm{Pal}-2)$ was dried in a convection oven at $100^{\circ} \mathrm{C}$ for $24 \mathrm{~h}$, ground, and sieved (70 mesh).

2.4. Pal Modification with the Phosphonium Surfactant. To produce a new organo-Pal, $25 \mathrm{~g}$ of $\mathrm{Pal}$ was mechanically dispersed in $2.5 \mathrm{~L}$ of distilled water for $1 \mathrm{~h}$ and then was filtered through a 70 mesh sieve and sonicated for $30 \mathrm{~min}$ (ultrasonic tip Vibra Cell, model $750 \mathrm{VC}$, at $20 \mathrm{kHz}$ ). Subsequently, HDTBP solution was slowly added to the Pal suspension; the amount of surfactant corresponded to the 1.1 CEC of Pal. The reaction was then maintained under mechanical stirring at $80^{\circ} \mathrm{C}$ for $5 \mathrm{~h}$ [9]. The modified Pal was washed several times with distilled water to remove the bromide ions. Finally, the modified Pal (Pal-3) was dried in a convection oven at $100^{\circ} \mathrm{C}$ for $24 \mathrm{~h}$, ground, and sieved (70 mesh).

2.5. Preparation of $P P / P P-g-M A H / P a l$ Nanocomposites. The dried Pals were melt-compounded separately with PP/PP-gMAH (containing $5 \mathrm{wt} \%$ of PP-g-MAH) in a batch mixer Plasticorder, Brabender at $190^{\circ} \mathrm{C}$ for $5 \mathrm{~min}$ at $100 \mathrm{rpm}$ to obtain PP/PP-g-MAH/Pal nanocomposites. Pal contents were $0.5,1$, and 2 wt. $\%$. Other studies have reported that the tensile mechanical properties of PP did not increase considerably at concentrations higher than $2 \mathrm{wt} . \%$ of Pal [35, 37]. The composites were compression molded at $190^{\circ} \mathrm{C}$ in a lab press for $3 \mathrm{~min}$ at $45 \mathrm{kN}$ clamping load; specimens for further characterization were obtained from the above plates $(120 \times 120 \mathrm{~mm}, 1 \mathrm{~mm}$ thick $)$.

\section{Characterization}

3.1. Scanning Electron Microscopy (SEM) and Transmission Electron Microscopy (TEM) Analysis. Pals and the fracture surfaces of PP/PP-g-MAH/Pal nanocomposites (under cryogenic conditions) were observed using a variable-pressure Scanning Electron Microscope Jeol model JSM-6360 LV $(20 \mathrm{kV})$; samples were coated with a thin layer of gold. TEM analysis was carried out with a Titán 80-300 k microscope, on ultrathin samples obtained by a microtome under cryogenic conditions.

3.2. Fourier Transform Infrared Spectroscopy (FTIR). FTIR analysis was carried out on Pals with a FTIR Nicolet 8700. $\mathrm{KBr} / \mathrm{Pal}$ tablets (2\% wt. clay) were obtained using a $\mathrm{KBr}$ pellet die applying a $20 \mathrm{kN}$ clamping load for $5 \mathrm{~min}$. The scanning 


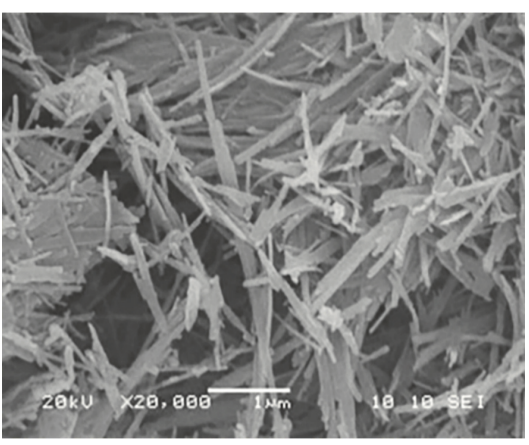

(a)

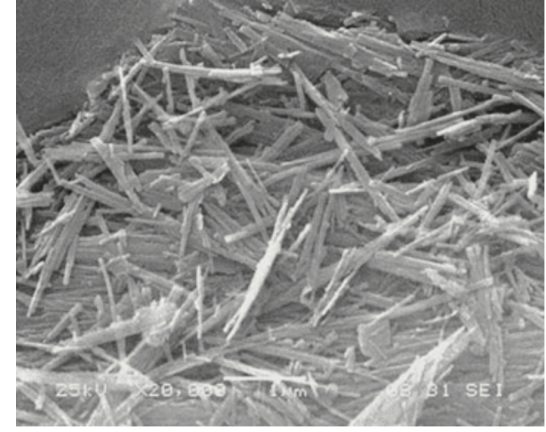

(b)

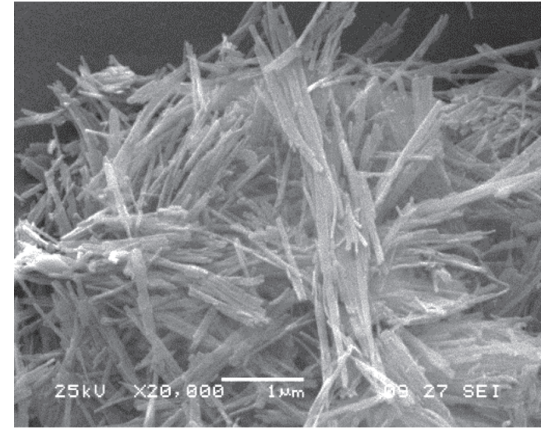

(c)

FIgURE 1: SEM micrographs for palygorskite samples: (a) Pal-1, (b) Pal-2, and (c) Pal-3.

range was from 4000 to $400 \mathrm{~cm}^{-1}$ with a resolution of $4 \mathrm{~cm}^{-1}$; the results are the average of 100 scans.

3.3. Thermogravimetric Analysis (TGA). The thermal stability of $\mathrm{PP} / \mathrm{PP}-\mathrm{g}-\mathrm{MAH} / \mathrm{Pal}$ nanocomposites was determined with a Thermogravimetric Analyzer TGA-7 Perkin Elmer, from $50^{\circ} \mathrm{C}$ to $700^{\circ} \mathrm{C}$ with a heating rate of $10^{\circ} \mathrm{C} / \mathrm{min}$ under a Nitrogen atmosphere; the sample weight was $5 \mathrm{mg}$.

3.4. Contact Angle Measurements. To assess the change in the hydrophilicity of Pal, the contact angles of sessile drops of ethylene glycol (Sigma-Aldrich) on the surface of $\mathrm{Pal}$ tablets were measured at room temperature. Pal tablets were prepared by compressing $300 \mathrm{mg}$ of $\mathrm{Pal}$ using a $\mathrm{KBr}$ pellet die applying $50 \mathrm{kN}$ clamping force for $5 \mathrm{~min}$ (Lab Carver Press). The values of contact angles were determined using the dynamic sessile drop method with a goniometer-Ramé-Hart Instrument Co model 250. The average contact angles were calculated from twenty measurements of four different drops.

3.5. Mechanical Tensile Properties. Mechanical tensile testing was carried out using a universal tensile machine (Mini SHIMADZU model AGS-1KN); specimens were deformed at $5 \mathrm{~mm} / \mathrm{min}$ at room temperature according to the standard test method ASTM-638D. Elastic modulus, tensile strength, and elongation at break were determined. The total length for the dog-bone specimen was $115 \mathrm{~mm}$, gauge length was $25 \mathrm{~mm}$, and the narrow section width was $6 \mathrm{~mm}$.

3.6. Differential Scanning Calorimetry (DSC). DSC analysis was carried out using a Perkin Elmer DSC-7 calorimeter under a Nitrogen atmosphere. The samples $(6 \mathrm{mg})$ were sealed in aluminum pans and heated from $50^{\circ} \mathrm{C}$ to $250^{\circ} \mathrm{C}$ at $10^{\circ} \mathrm{C} / \mathrm{min}$ and cooled at $50^{\circ} \mathrm{C} / \mathrm{min}$; two heating runs were conducted.

\section{Results and Discussion}

4.1. Morphology of Pals. The morphology of Pals was assessed by SEM micrographs (Figure 1). The morphology of Pal-1 is presented as a fibrillar structure (Figure 1(a)); the diameter ranges from 20 to $30 \mathrm{~nm}$ and the length shows a wide range

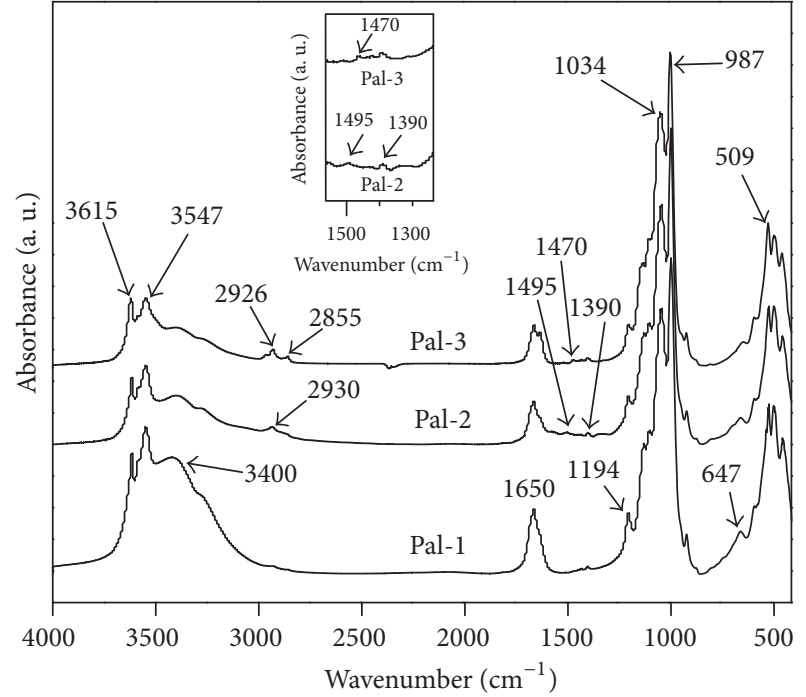

FIgURe 2: FT-IR spectra of Pal-1, Pal-2, and Pal-3.

from hundreds of nanometers to few microns. In addition, Pal was observed as agglomerates due to the strong interactions among individual silicate fibers [15]. SEM micrographs of Pal-2 (Figure 1(b)) revealed no substantial changes in the clay fiber morphology after silane treatment. Clay aggregates seem to be more compact; it may be possible therefore that silane molecules can contribute to the aggregation among clay particles. Finally, Figure 1(c) shows Pal-3 fibers; some clay particles appear to be separated from the agglomerates, possibly due to the weakened clay-clay interactions after the surface modification. The SEM observations suggest that the experimental conditions used during surface modification of Pal did not significantly modify the aspect ratio morphology.

4.2. FT-IR Characterization. FT-IR analysis was conducted to verify the surface modification of Pal; the FT-IR spectra of Pal-1, Pal-2, and Pal-3 are presented in Figure 2. The band in $3615 \mathrm{~cm}^{-1}$ for the Pal-1 spectrum can be attributed to the stretching vibrations of $\mathrm{Mg}-\mathrm{OH}$ from the dioctahedral 


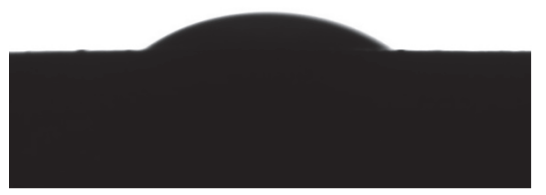

(a)

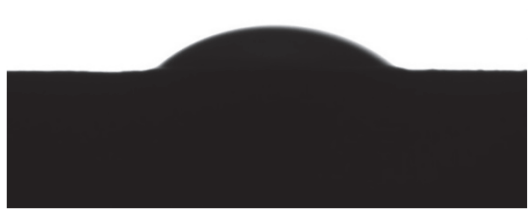

(b)

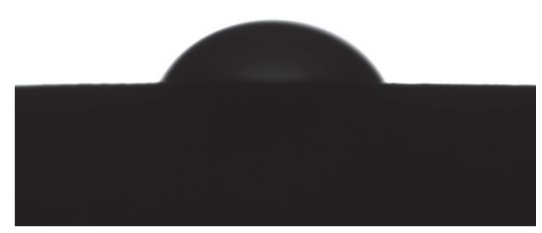

(c)

Figure 3: Profiles of sessile drops of ethylene glycol on the surfaces of: (a) Pal-1, (b) Pal-2, and (c) Pal-3, respectively.

units. A band associated with the stretching vibrations of the coordinated water is observed at $3547 \mathrm{~cm}^{-1}$ [41]. The band at $3400 \mathrm{~cm}^{-1}$ corresponds to the stretching vibrations of absorbed and zeolitic water. The band at $1650 \mathrm{~cm}^{-1}$ was attributed to $\mathrm{OH}$ bending vibrations of coordinated, absorbed, and zeolite water [3]; it is probable that the above band could overlap the signal associated with vibrations of the amino groups from silane molecules at $1608 \mathrm{~cm}^{-1}$. The bands at $1194 \mathrm{~cm}^{-1}$ and $1034 \mathrm{~cm}^{-1}$ were attributed to asymmetric stretching vibrations from Si-O. The band in $987 \mathrm{~cm}^{-1}$ is due to vibrations stretching perpendicularly to the plane of $\mathrm{Si}-\mathrm{O}$, and the band at $647 \mathrm{~cm}^{-1}$ could be attributed to stretching vibrations from $\mathrm{Mg}$ bonded water (zeolitic and surface absorbed) [42]. The signal in $509 \mathrm{~cm}^{-1}$ corresponds to the deformation of Si-O bonds from tetrahedral sheets [41]. The IR signals are consistent with the results reported in other studies.

The FT-IR spectrum for Pal-2 shows additional bands, for example, a band at $2930 \mathrm{~cm}^{-1}$ corresponding to the stretching vibrations of $\mathrm{C}-\mathrm{H}$ bonds from the silane molecule $[43,44]$. Bands associated with the symmetric bending vibrations for $\mathrm{N}-\mathrm{H}$ due to the amino groups of the silane grafted on the surface of Pal were observed at $1495 \mathrm{~cm}^{-1}$ and $1390 \mathrm{~cm}^{-1}$ [44]. On the other hand, the bands at 2926 and $2855 \mathrm{~cm}^{-1}$ in the FT-IR spectrum for Pal-3 correspond to the symmetric and antisymmetric stretching vibrations from $-\mathrm{CH}_{2}$ - groups of surfactant, respectively $[9,20]$. The band in $1470 \mathrm{~cm}^{-1}$ corresponds to the deformation of $\mathrm{C}-\mathrm{H}$ bonds [45] from the alkyl chains of surfactant. The experimental evidence suggests that the silane and cation surfactant molecules were successfully grafted to the Pal surface.

4.3. Contact Angle Measurements. Contact angle measurements have been reported for other mineral clays such as montmorillonite (MMT) [46-48], kaolinite [49], and smectite [50] for the purpose of verifying the surface modification of clays. Figure 3 shows profiles of the sessile droplets of ethylene glycol on the surfaces of Pal tablets. Ethylene glycol was chosen as test liquid due to its viscosity and polarity. The average values of the contact angle for the Pals are shown in Table 1, which tend to increase with the surface treatment. Pal-1 belongs to a type of natural hydrophilic silicate showing hydrophilic nature; as a consequence, the contact angle of a sessile droplet of a partial hydrophilic was small. The increment in the contact angle for other Pals can be interpreted as an increase in the hydrophobicity of the Pal
TABLE 1: Contact angles for ethylene glycol on three types of Pal.

\begin{tabular}{lc}
\hline Sample & $\theta\left(^{\circ}\right)$ \\
\hline Purified-Pal & $14.01 \pm 0.99$ \\
APTMS-Pal & $20.09 \pm 2.27$ \\
HDTBP-Pal & $23.04 \pm 2.87$ \\
\hline
\end{tabular}

surface due to the hydrophobic silane coupling agent or the cationic surfactant grafted to the surface. The enhancement of hydrophobicity in the organically modified clays could lead to an improvement in the dispersion/exfoliation of clay within the polymer [51].

4.4. Pal Dispersion within the PP/PP-g-MAH/Pal Nanocomposites. The dispersion of $\mathrm{Pal}$ within $\mathrm{PP}$ matrix was determined by SEM observations (Figure 4) of the fracture surfaces of PP/PP-g-MAH/Pal nanocomposites with three different types of Pal ( 2 wt.\% Pal content). Figures 4(a)-4(c) correspond to Pal-1 nanocomposites at different magnifications, in which Pal-1 was distributed as aggregates in micrometer size; the light dots are the fractured ends of fibrous crystals of Pal. Figures 4(d)-4(f) correspond to PP/PP-g-MA/Pal2 nanocomposites where Pal- 2 was distributed as smaller agglomerates; the results suggest that Pal dispersion was improved with the surface treatment due to the weakening of interactions among palygorskite single crystals. Weaker interactions among fibers allow the separation of Pal crystals from the bundles during the melt compounding [16]. Finally, Figures 4(g)-4(i) correspond to PP/PP-g-MA/Pal-3 nanocomposites. Interestingly, small aggregates were found on the fractured surface indicating good distribution and dispersion of Pal. The experimental evidence suggests that the surfactant modification of Pal effectively improved the compatibility among components, resulting in a uniform distribution and dispersion of Pal and inhibition of Pal reagglomeration.

TEM images of the PP/PP-g-MA/Pal nanocomposites at $2 \% \mathrm{w} / \mathrm{w}$ Pal content are shown in Figure 5. In Figures 5(a)-5(c), aggregates of Pal-1 with diameters around $193 \mathrm{~nm}$ are observed; the measurements were carried out using ImageJ software. On the other hand, in Figures 5(d)-5(f), the silicate fibers of Pal-2 are dispersed within the polymer matrix with aggregates with diameter around $144 \mathrm{~nm}$. The Figure $5(\mathrm{~g})$ shows the transversal view of Pal-3 fibers well dispersed within the PP/PP-g-MAH blend. Figures 5(h)-5(i) show details of the distribution and dispersion of Pal-3; the 


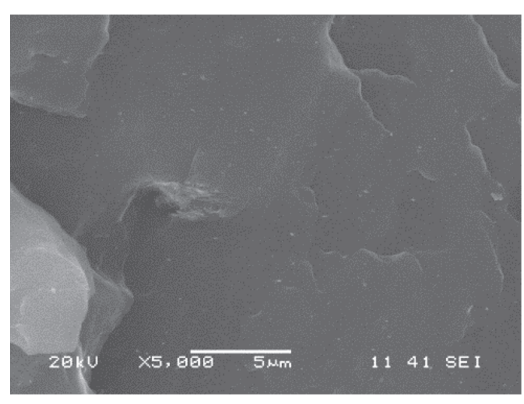

(a)

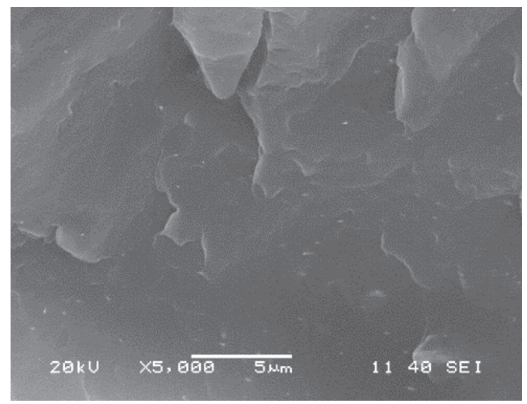

(d)

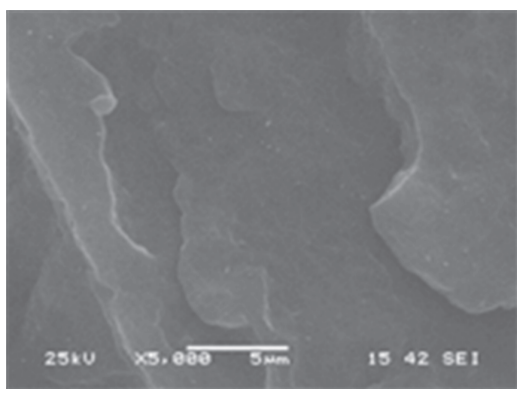

(g)

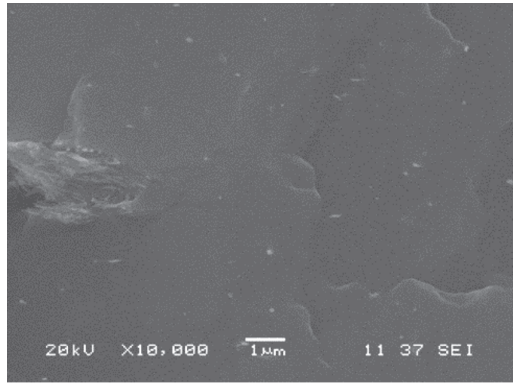

(b)

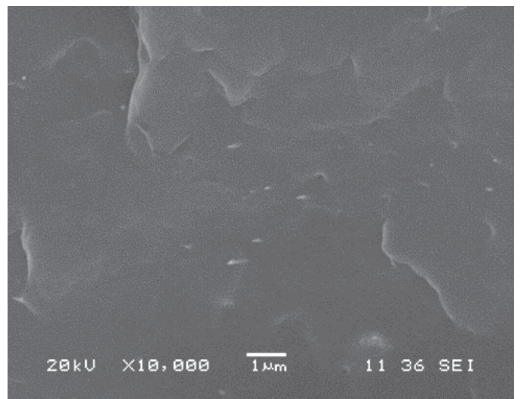

(e)

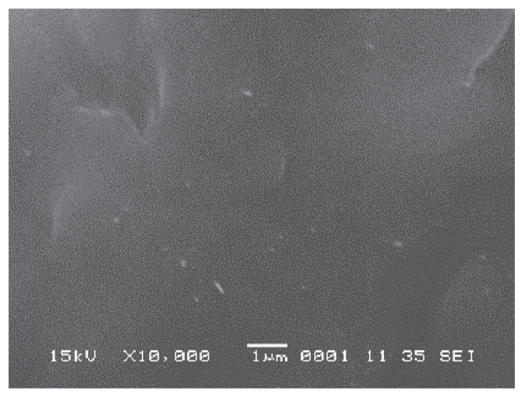

(h)

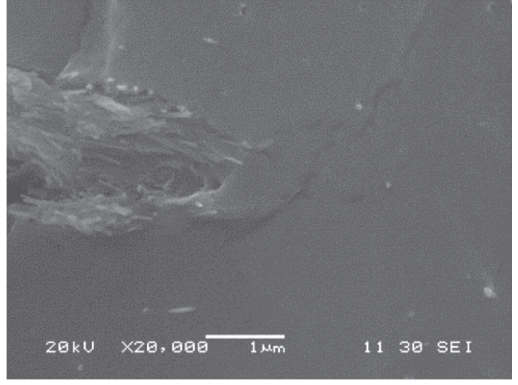

(c)

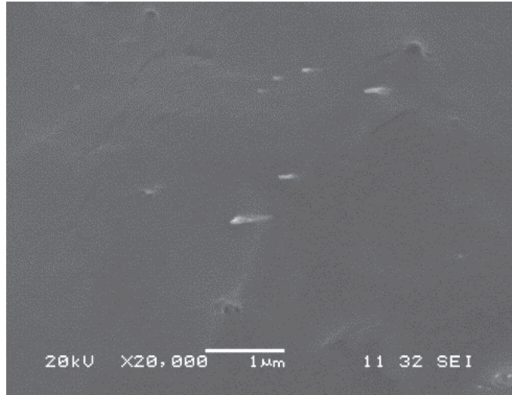

(f)

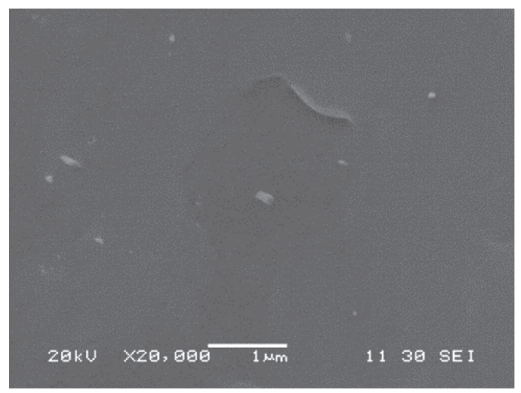

(i)

Figure 4: SEM micrographs of the fractured surface at different magnifications of PP/PP-g-MAH/Pal nanocomposites (2 wt.\%): Pal-1 (a), (b), and (c); Pal-2 (d), (e), and (f); Pal-3 (g), (h), and (i).

diameter of Pal-3 aggregate ranges from 20 to $40 \mathrm{~nm}$. The results indicate that the distribution and dispersion of silicate fibers depend on the reduction of surface energy of Pal: Pal-3 modified with longer alkane molecules shows better dispersion and distribution.

4.5. Mechanical Properties. The tensile mechanical properties of PP/PP-g-MAH/Pal nanocomposites are shown in Figure 6. In general, Young's modulus (Figure 6(a)) increased with Pal concentration due to the stiffness of silicate fibers, depending on the surface modification of Pal. For instance, the modulus of PP/PP-g-MAH/Pal-1 nanocomposites increase rapidly with a Pal load at low concentration (0.5 and $1 \mathrm{wt} . \%)$, while, at higher Pal content, the modulus reaches a plateau. It may be that, at this relatively high concentration of $\mathrm{Pal}$, the agglomeration of silicate fibers acts as a stress concentrator, as reported in other studies [35, 37].

However, the nanocomposites containing Pal-2 and Pal3 exhibited higher values of Young's modulus compared with
Pal-1 nanocomposites; the results suggest that the reduction of surface energy of silicate fibers promoted its dispersion and compatibility with the polymeric matrix, increasing the stiffness of nanocomposites at low concentration of Pals. There are no significant differences in the modulus with the experimental error for Pal-2 and Pal-3 nanocomposites.

On the other hand, the tensile strength of PP (Figure 6(b)) increased slightly with the addition of Pals; however, no significant differences were observed with the experimental error. It is important to point out that the strength of the polymer matrix was not only preserved but actually slightly improved; it has also been reported that the inclusion of mineral filler within PP tends to reduce the matrix strength [52]. Further studies are required in order to promote the polymer-Pal interactions by increasing the content of PP-gMAH to improve the mechanical properties.

It is widely accepted that the incorporation of nanoreinforcers in polymeric materials tends to reduce the elongation at break of nanocomposites. The experimental results 


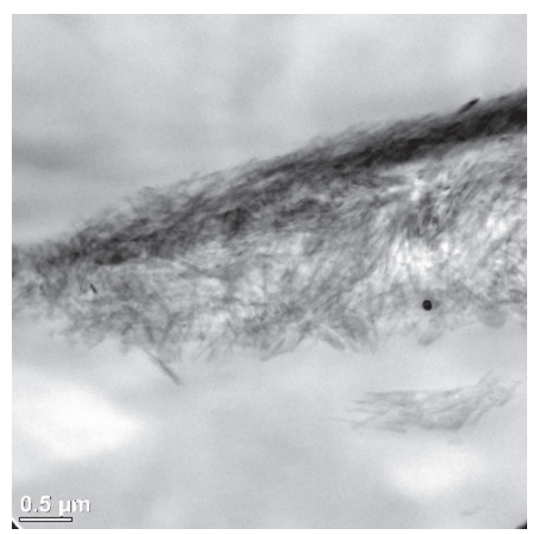

(a)

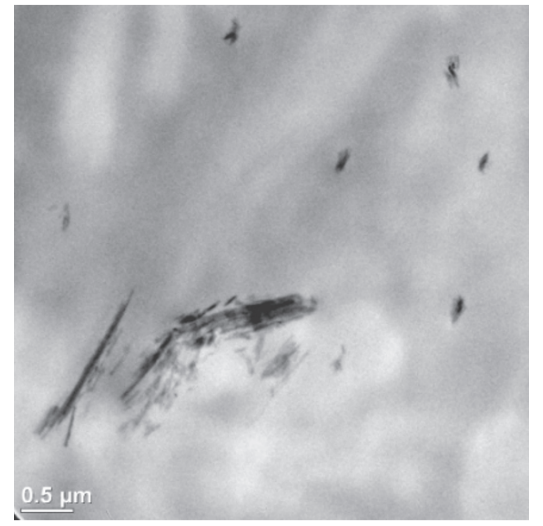

(d)

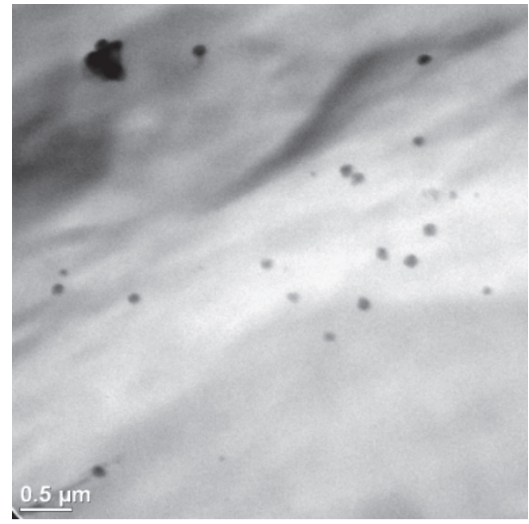

(g)

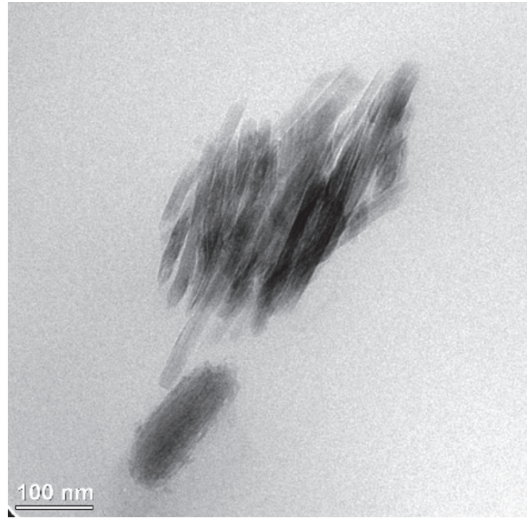

(b)

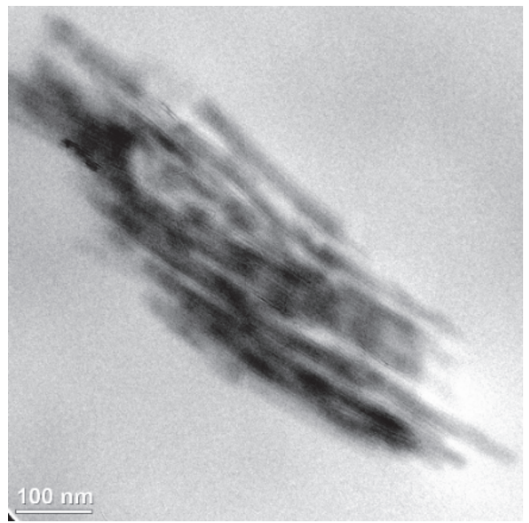

(e)

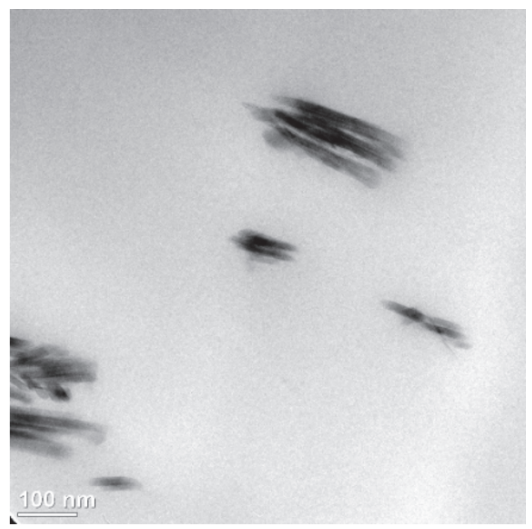

(h)

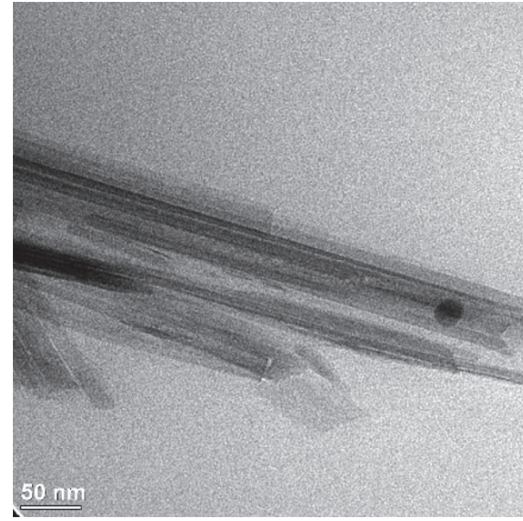

(c)

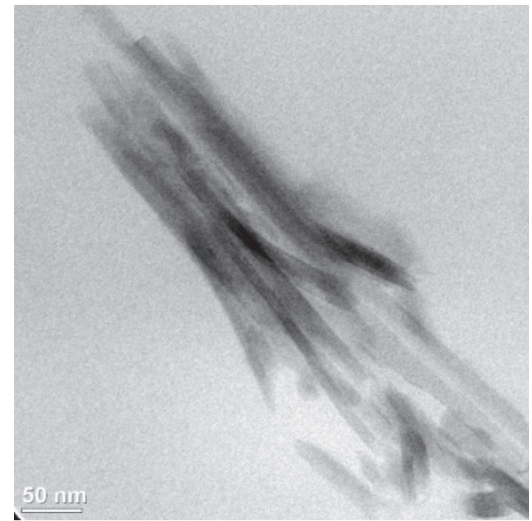

(f)

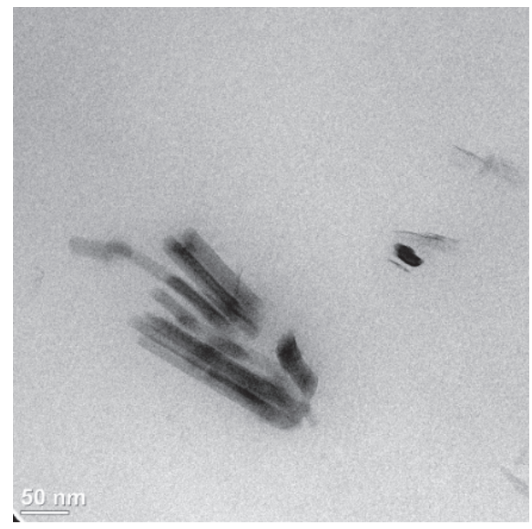

(i)

Figure 5: TEM micrographs of PP/PP-g-MAH/Pal nanocomposites: Pal-1 ((a) to (c)), Pal-2 ((d) to (f)), and Pal-3 ((g) to (i)).

concerning elongation at break (Figure 6(c)) indicate that the property decreases with the Pal content (regardless of the type of Pal used), possibly due to the restriction in molecular movement of the polymer chains between silicate fibers and/or Pal agglomeration $[31,53]$.

4.6. Thermal Properties. The TGA analysis provides relevant information concerning the thermal stability of the nanocomposites. The TGA traces in Figure 7 depict the variations of the residual mass as a function of temperature for pure PP, PP/PP-g-MAH, and PP/PP-g-MAH/Pal nanocomposites. TGA traces for PP and PP PP-g-MAH (Figure 7(a)) show that the thermal decomposition of the materials occurs in one step; PP/PP-g-MAH seems to be slightly less thermally stable than PP due to the lower molecular weight of the compatibilizer. TGA traces of Pal-1 nanocomposites were shifted at higher temperatures especially at 1 and $2 \%$ wt. of Pal-1. On the other hand, the TGA traces of nanocomposites containing Pal-2 showed a drastic shift toward higher temperatures with the inclusion of Pal-2 even at the lowest 


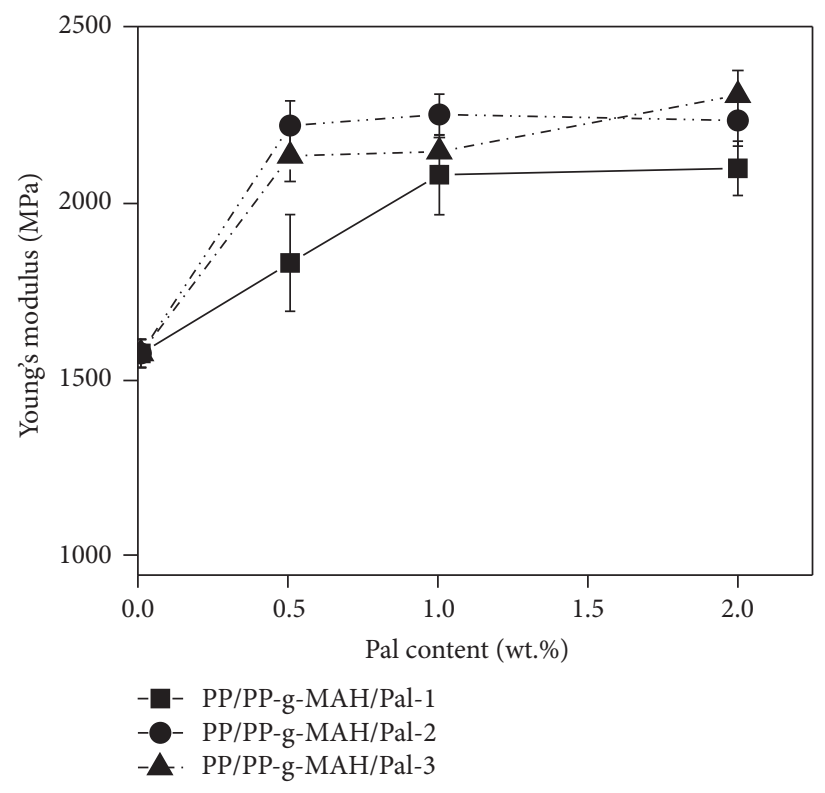

(a)

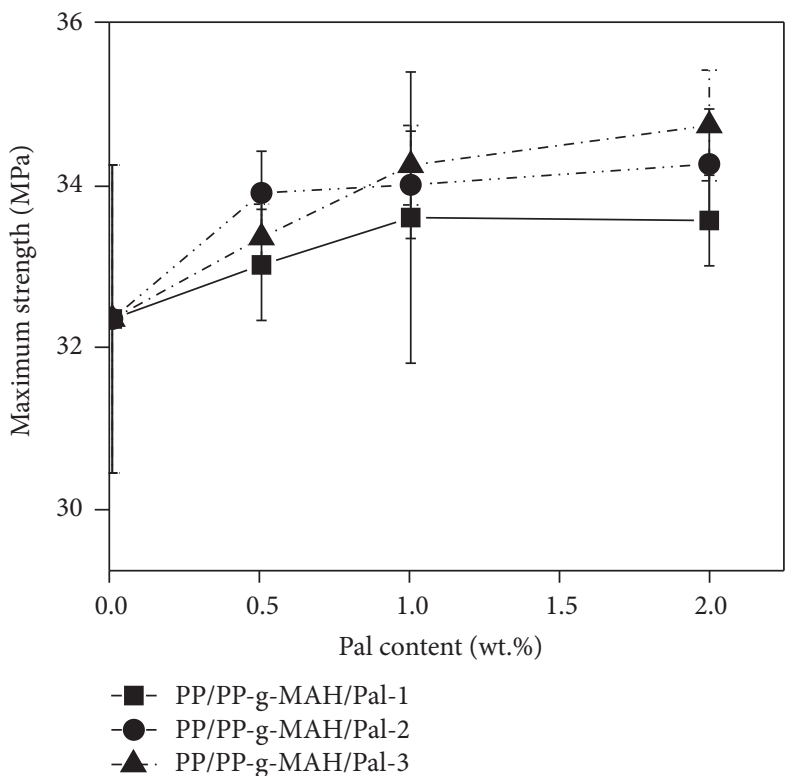

(b)

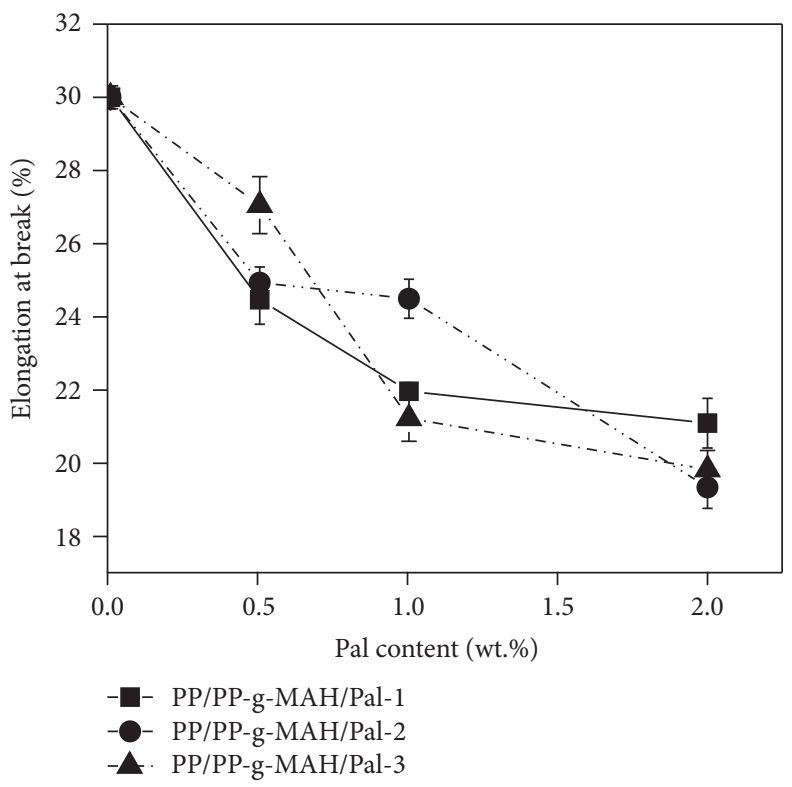

(c)

FIGURE 6: Mechanical properties of PP/PP-g-MAH/Pal nanocomposites: (a) Young's modulus, (b) maximum strength, and (c) elongation at the break.

concentration of Pal-2 and thermal stability increased with filler concentration (Figure $7(\mathrm{~b})$ ). The thermal stability of PP/PP-g-MAH/Pal-3 nanocomposites (Figure 7(c)) presents an interesting behavior: the TGA traces were shifted to higher temperatures at low content of Pal-3 and the thermal stability remained, regardless of the Pal-3 content. The results suggest that the thermal stability of PP nanocomposites depended on the degree of Pal dispersion promoted by the surface modification, with the Pal modified with the phosphonium surfactant producing the best results. The improvement in the thermal stability of $\mathrm{PP} /$ clay nanocomposites is attributed to a barrier effect of the dispersed particles of the clay, which can minimize the permeability of the volatile degradation products from the nanocomposites [31, 53], as well as the higher thermal stability of clays modified with phosphonium surfactants $[54,55]$.

The effect of Pal dispersion on the crystallinity of PP was evaluated by DSC. Figure 8 shows the DSC traces (corresponding to the second heating run) for PP, PP/PP-g$\mathrm{MAH}$, and PP/PP-g-MAH/Pal nanocomposites as a function of type and concentration of Pal. PP exhibited a melting peak at $165.1^{\circ} \mathrm{C}$ and $\mathrm{PP} / \mathrm{PP}-\mathrm{g}-\mathrm{MAH}$ at $165.8^{\circ} \mathrm{C}$. In general, 


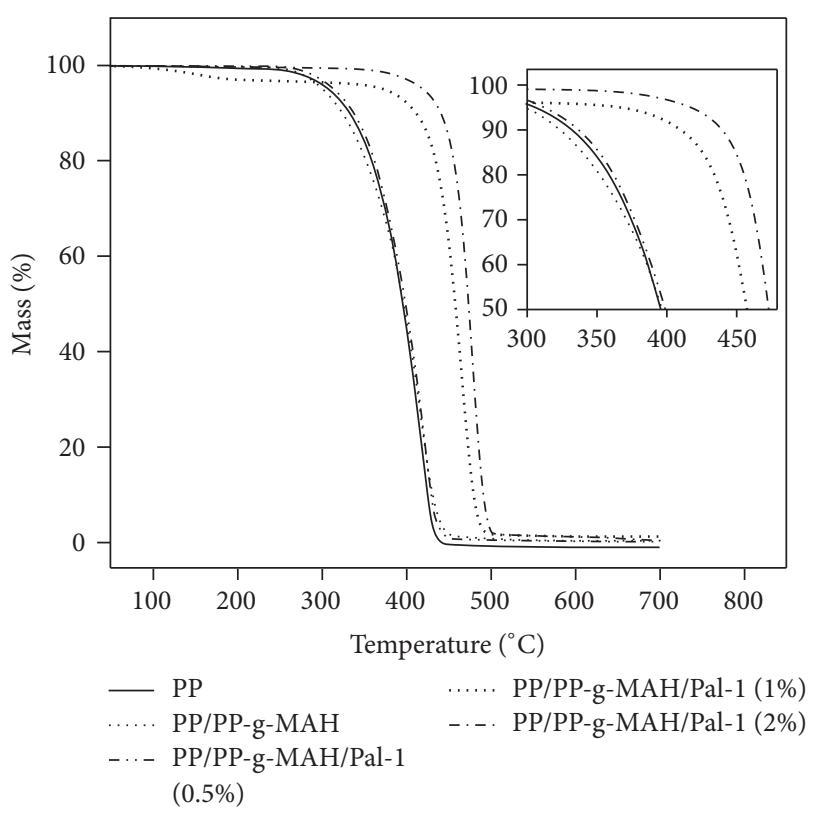

(a)

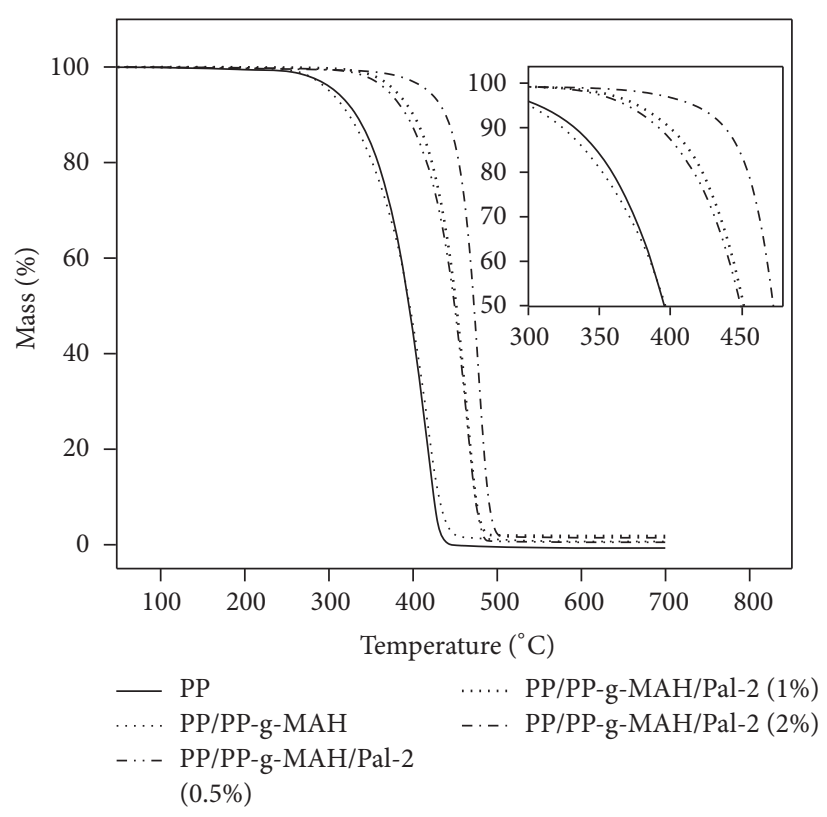

(b)

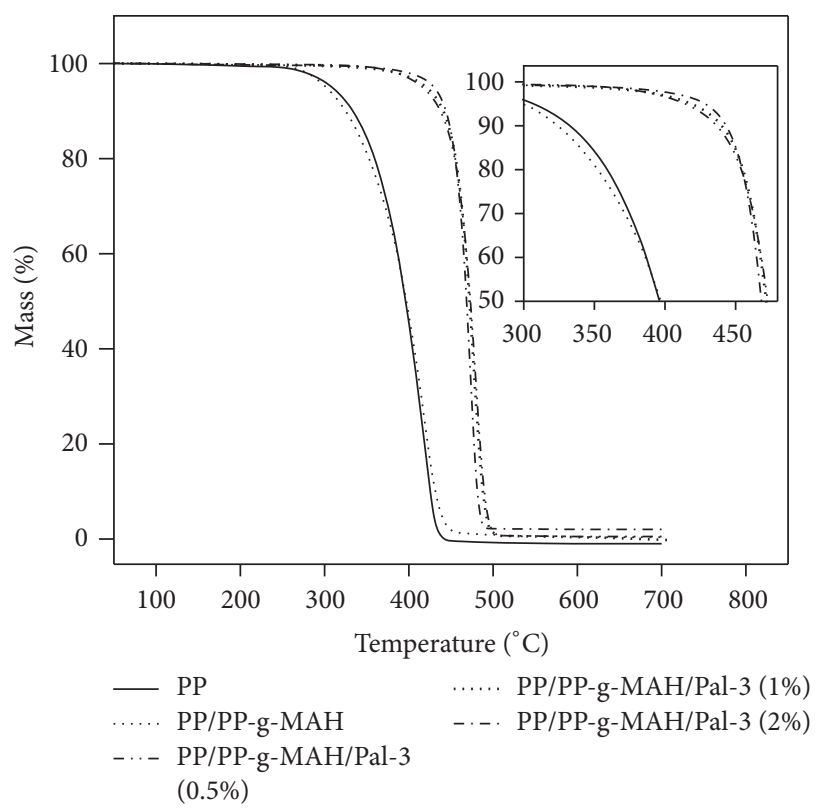

(c)

Figure 7: TGA traces for PP and PP/PP-g-MAH/Pal nanocomposites (0.5, 1, and 2 wt.\% Pal content): (a) Pal-1, (b) Pal-2, and (c) Pal-3.

Pal nanocomposites exhibited the melting peak in the same temperature range. Table 2 depicts the melting point $\left(T_{m}\right)$, melting enthalpy $\left(\Delta H_{c}\right)$, and the degree of crystallinity $\left(X_{c}\right)$. The degree of crystallinity was calculated considering the melting enthalpy for $100 \%$ crystalline PP to be $190.6 \mathrm{~J} / \mathrm{g}$ [56]. A slight shift of the melting temperatures of nanocomposites to lower temperatures was observed, which might be related to the reduction in the crystallite size due to the presence of palygorskite [57].

The degree of crystallinity of PP matrix from nanocomposites tends to increase with Pal content, regardless of the surface treatment. $\mathrm{PP} / \mathrm{PP}-\mathrm{g}-\mathrm{MAH} / \mathrm{Pal}-1$ shows lower values in the degree of crystallinity given that the Pal agglomerates reduce the concentration of active sites for nucleation [58]. Thus, the better dispersed Pal-2 and Pal-3 in nanocomposites act as effective nucleation agents, increasing slightly the degree of crystallinity.

\section{Conclusions}

The effect of surface modification of Pal on filler dispersion and the mechanical and thermal properties was evaluated. 


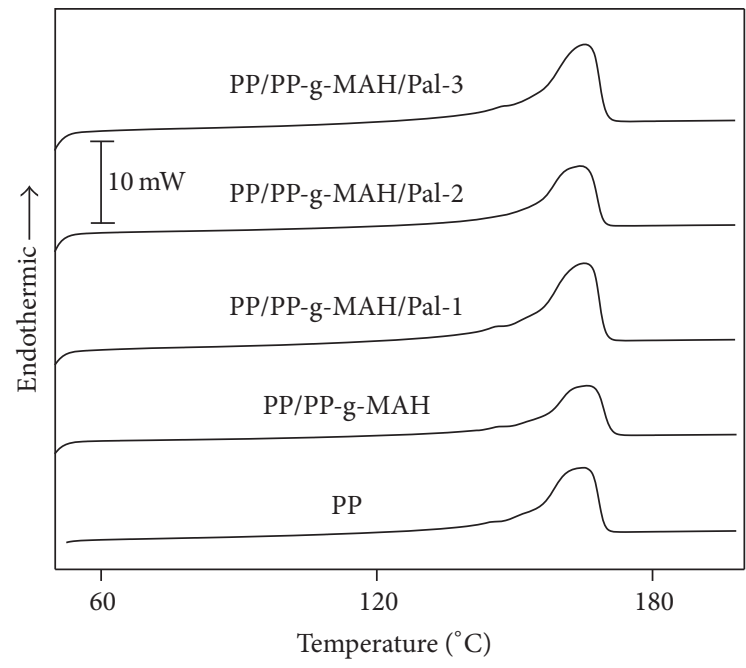

(a)

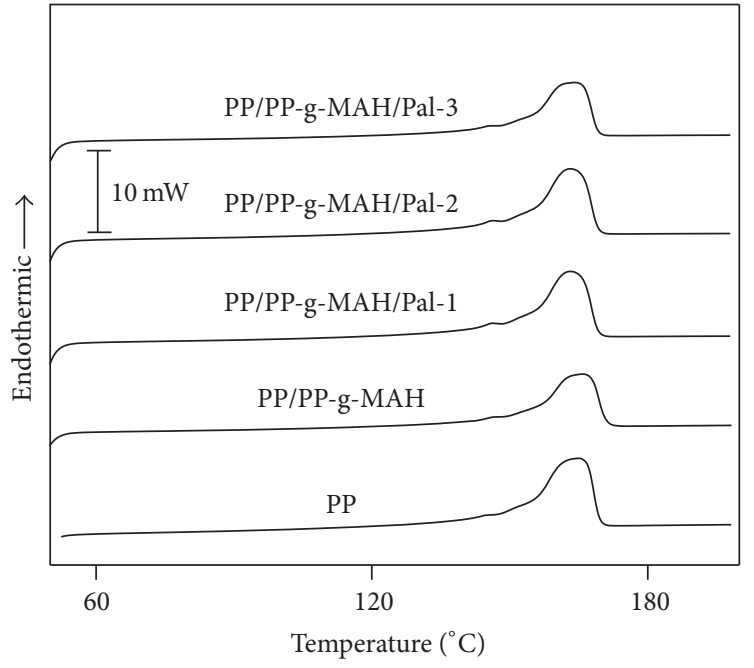

(b)

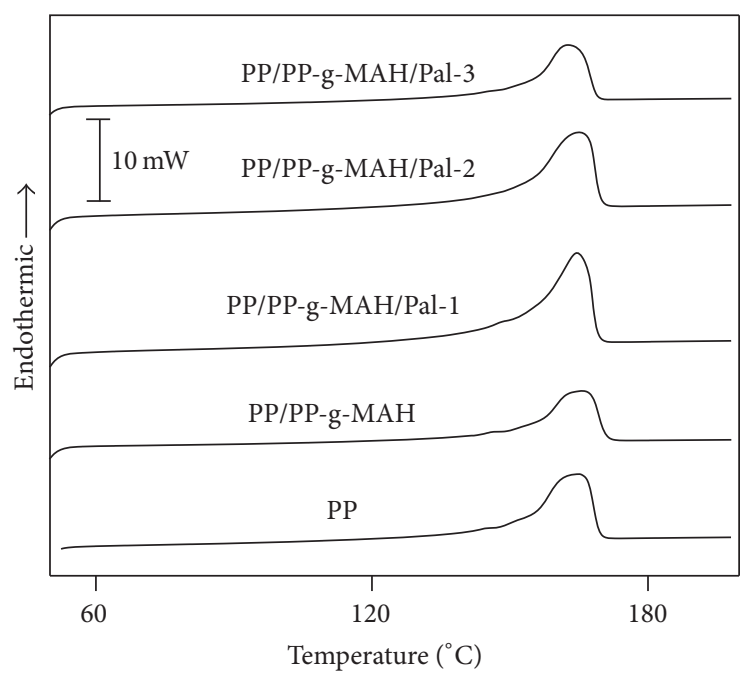

(c)

Figure 8: DSC thermograms for PP, PP/PP-g-MAH, and PP/PP-g-MAH/Pal: (a) 0.5, (b) 1, and (c) 2 wt.\% Pal content, respectively.

TABLE 2: DSC parameters for PP and PP/PP-g-MAH/Pal nanocomposites.

\begin{tabular}{|c|c|c|c|}
\hline Sample & $\operatorname{Tm}\left({ }^{\circ} \mathrm{C}\right)$ & $\Delta H_{c}(\mathrm{~J} / \mathrm{g})$ & $X_{c}(\%)$ \\
\hline $\mathrm{PP}$ & 165.1 & 79.7 & 41.8 \\
\hline PP/PP-g-MAH & 165.8 & 79.9 & 42.7 \\
\hline PP/PP-g-MAH/Pal-1 (0.5\% w/w) & 165.2 & 79.3 & 41.8 \\
\hline PP/PP-g-MAH/Pal-1 (1\% w/w) & 164.2 & 80.4 & 42.4 \\
\hline PP/PP-g-MAH/Pal-1 (2\% w/w) & 162.9 & 79.8 & 41.9 \\
\hline PP/PP-g-MAH/Pal-2 (0.5\% w/w) & 165.3 & 80.2 & 42.5 \\
\hline PP/PP-g-MAH/Pal-2 (1\% w/w) & 164.3 & 80.6 & 42.7 \\
\hline PP/PP-g-MAH/Pal-2 (2\% w/w) & 163.5 & 81.4 & 43.6 \\
\hline PP/PP-g-MAH/Pal-3 (0.5\% w/w) & 164.3 & 82.6 & 44.2 \\
\hline PP/PP-g-MAH/Pal-3 (1\% w/w) & 163.1 & 80.9 & 42.7 \\
\hline PP/PP-g-MAH/Pal-3 (2\% w/w) & 163.2 & 83.6 & 44.8 \\
\hline
\end{tabular}


Natural palygorskite was purified and surface modified separately to produce a silane modified Pal and a new phosphonium surfactant modified Pal. PP/PP-g-MAH/Pal nanocomposites were melt-compounded with different concentration of Pals. FT-IR analysis confirmed the surface modification of $\mathrm{Pal}$ and the contact angle measurements suggested that hydrophilicity of Pal was slightly reduced with the surface modification.

Pal particles were dispersed in different manners depending on the surface treatment. Pristine Pal was poorly distributed/dispersed within PP; however, Pal dispersion was improved when the surface of Pal was modified with a silane coupling agent or cationic surfactant, and the latter was better dispersed. It is possible that the longer alkyl chains of the cationic surfactant promoted interactions among polymer chains and modified Pal, thereby improving the dispersion. Young's modulus increased and maximum strength slightly improved with Pal content, and elongation at the break tended to decrease. As expected, samples with improved dispersion of Pal exhibited relatively improved mechanical properties. On the other hand, the thermal stability of nanocomposites depended on the degree of Pal dispersion; contrarily, the crystallinity of the nanocomposites is affected slightly by $\mathrm{Pal}$, at least under the conditions described in this study.

\section{Conflicts of Interest}

The authors declare that they have no conflicts of interest.

\section{Acknowledgments}

The present study was financially supported by FOMIX-Yuca$\tan$ Grant 6030200001 and the Conacyt-Mexico Grant no. 222908. The technical support from Rossana Vargas-Coronado and Santiago Duarte-Aranda on FTIR analysis and SEM observations is highly appreciated.

\section{References}

[1] L. Wang and J. Sheng, "Preparation and properties of polypropylene/org-attapulgite nanocomposites," Polymer, vol. 46, no. 16, pp. 6243-6249, 2005.

[2] A. K. Helmy, S. G. de Bussetti, and E. A. Ferreiro, "The surface energy of palygorskite," Powder Technology, vol. 171, no. 2, pp. 126-131, 2007.

[3] R. Wang, Z. Li, Y. Wang et al., "Effects of modified attapulgite on the properties of attapulgite/epoxy nanocomposites," Polymer Composites, vol. 34, no. 1, pp. 22-31, 2013.

[4] E. Ruiz-Hitzky, M. Darder, A. C. S. Alcântara, B. Wicklein, and P. Aranda, "Functional nanocomposites based on fibrous clays," RSC Smart Materials, pp. 1-53, 2016.

[5] J.-L. Cao, G.-S. Shao, Y. Wang, Y. Liu, and Z.-Y. Yuan, "CuO catalysts supported on attapulgite clay for low-temperature $\mathrm{CO}$ oxidation," Catalysis Communications, vol. 9, no. 15, pp. 25552559, 2008.

[6] S. Guo and L. Shi, "Synthesis of succinic anhydride from maleic anhydride on Ni/diatomite catalysts," Catalysis Today, vol. 212, pp. 137-141, 2013.

[7] P. Pushpaletha and M. Lalithambika, "Modified attapulgite: an efficient solid acid catalyst for acetylation of alcohols using acetic acid," Applied Clay Science, vol. 51, no. 4, pp. 424-430, 2011.

[8] A. Xue, S. Zhou, Y. Zhao, X. Lu, and P. Han, "Effective NH2grafting on attapulgite surfaces for adsorption of reactive dyes," Journal of Hazardous Materials, vol. 194, pp. 7-14, 2011.

[9] Y. Xi, M. Mallavarapu, and R. Naidu, "Adsorption of the herbicide 2,4-D on organo-palygorskite," Applied Clay Science, vol. 49, no. 3, pp. 255-261, 2010.

[10] G. Tian, Y. Kang, B. Mu, and A. Wang, "Attapulgite modified with silane coupling agent for phosphorus adsorption and deep bleaching of refined palm oil," Adsorption Science \& Technology, vol. 32, no. 1, pp. 37-48, 2014.

[11] X. Yuan, C. Li, G. Guan, X. Liu, Y. Xiao, and D. Zhang, "Synthesis and characterization of poly(ethylene terephthalate)/ attapulgite nanocomposites," Journal of Applied Polymer Science, vol. 103, no. 2, pp. 1279-1286, 2007.

[12] L. Wang and J. Sheng, "Graft polymerization and characterization of butyl acrylate onto silane-modified attapulgite," Journal of Macromolecular Science - Pure and Applied Chemistry, vol. 40, no. 11, pp. 1135-1146, 2003.

[13] L. Zhang, Q. Jin, J. Huang, Y. Liu, L. Shan, and X. Wang, "Modification of palygorskite surface by organofunctionalization for application in immobilization of H 3 PW 12 O 40," Applied Surface Science, vol. 256, no. 20, pp. 5911-5917, 2010.

[14] B. Pan, Q. Yue, J. Ren et al., "A study on attapulgite reinforced PA6 composites," Polymer Testing, vol. 25, no. 3, pp. 384-391, 2006.

[15] C. Subramani, V. S. Jamnik, and S. T. Mhaske, "Effect of attapulgite filler on the properties of nylon-6," Polymer Composites, vol. 29, no. 8, pp. 890-893, 2008.

[16] J. Shi, X. Yang, Q. Han, X. Wang, and L. Lu, "Polyurethane grafted attapulgite as novel fillers for nylon 6 nanocomposites," Journal Wuhan University of Technology, Materials Science Edition, vol. 26, no. 4, pp. 615-619, 2011.

[17] L. Xia, B. Shentu, and Z. Weng, "Effect of dendrimer-like PAMAM grafted attapulgite on the microstructure and morphology of Nylon-6," Polymer Composites, vol. 35, no. 4, pp. 627635, 2014.

[18] N. Othman, S. N. A. Muttalib, and N. I. Ismail, "The effect of surface modification on the properties of palygorskite filled natural rubber nanocomposite," Macromolecular Symposia, vol. 371, no. 1, pp. 35-43, 2017.

[19] L. Shao, Z. Ji, J. Ma, C. Xue, and F. Deng, "Morphology and interaction of nanocomposite foams formed with organopalygorskite and ethylene-vinyl acetate copolymers," Polymer Bulletin, vol. 74, no. 2, pp. 413-429, 2016.

[20] X. Lei, Y. Liu, and Z. Su, "Synthesis and characterization of organo-attapulgite/ polyaniline- dodecylbenzenesulfonic acid based on emulsion polymerization method," Polymer Composites, vol. 29, no. 3, pp. 239-244, 2008.

[21] J. Huang, X. Wang, Q. Jin, Y. Liu, and Y. Wang, "Removal of phenol from aqueous solution by adsorption onto OTMACmodified attapulgite," Journal of Environmental Management, vol. 84, no. 2, pp. 229-236, 2007.

[22] Y. Chang, X. Lv, F. Zha, Y. Wang, and Z. Lei, "Sorption of pnitrophenol by anion-cation modified palygorskite," Journal of Hazardous Materials, vol. 168, no. 2-3, pp. 826-831, 2009.

[23] B. Sarkar, M. Megharaj, Y. Xi, and R. Naidu, "Surface charge characteristics of organo-palygorskites and adsorption of $\mathrm{p}$ nitrophenol in flow-through reactor system," Chemical Engineering Journal, vol. 185-186, pp. 35-43, 2012. 
[24] B. Sarkar, Y. Xi, M. Megharaj, and R. Naidu, "Orange II adsorption on palygorskites modified with alkyl trimethylammonium and dialkyl dimethylammonium bromide - an isothermal and kinetic study," Applied Clay Science, vol. 51, no. 3, pp. 370-374, 2011.

[25] R. Dong, Y. Liu, X. Wang, and J. Huang, "Adsorption of sulfate ions from aqueous solution by surfactant-modified palygorskite," Journal of Chemical \& Engineering Data, vol. 56, no. 10, pp. 3890-3896, 2011.

[26] H. A. Maddah, "Polypropylene as a promising plastic: a review," American Journal of Polymer Science, vol. 6, no. 1, pp. 1-11, 2016.

[27] M. Kawasumi, N. Hasegawa, M. Kato, A. Usuki, and A. Okada, "Preparation and mechanical properties of polypropylene-clay hybrids," Macromolecules, vol. 30, no. 20, pp. 6333-6338, 1997.

[28] J. A. Tarapow, C. R. Bernai, and V. A. Alvarez, "Mechanical properties of polypropylene/clay nanocomposites: effect of clay content, polymer/clay compatibility, and processing conditions," Journal of Applied Polymer Science, vol. 111, no. 2, pp. 768-778, 2009.

[29] J. J. Chen, J. Y. Chen, S. P. Zhu, Y. Cao, and H. L. Li, "Mechanical properties, morphology, and crystal structure of polypropylene/chemically modified attapulgite nanocomposites," Journal of Applied Polymer Science, vol. 121, no. 2, pp. 899-908, 2011.

[30] L. G. Furlan, C. I. Ferreira, C. Dal Castel et al., "Effect of processing conditions on the mechanical and thermal properties of high-impact polypropylene nanocomposites," Materials Science and Engineering: A, vol. 528, no. 22, pp. 6715-6718, 2011.

[31] W. C. Liaw, P. C. Huang, C. S. Chen, C. L. Lo, and J. L. Chang, "PPgMA/APTS compound coupling compatabilizer in PP/Clay hybrid nanocomposite," Journal of Applied Polymer Science, vol. 109, no. 3, pp. 1871-1880, 2008.

[32] N. G. Karsli and A. Aytac, "Effects of maleated polypropylene on the morphology, thermal and mechanical properties of short carbon fiber reinforced polypropylene composites," Materials and Design, vol. 32, no. 7, pp. 4069-4073, 2011.

[33] S. S. Ray and M. Okamoto, "Polymer/layered silicate nanocomposites: a review from preparation to processing," Progress in Polymer Science, vol. 28, no. 11, pp. 1539-1641, 2003.

[34] J. Hari, Z. Dominkovics, E. Fekete, and B. Pukánszky, "Kinetics of structure formation in PP/layered silicate nanocomposites," Express Polymer Letters, vol. 3, no. 11, pp. 692-702, 2009.

[35] J. Chen, J. Chen, S. Zhu, Y. Cao, and H. Li, "Mechanical properties, morphology, and crystal structure of polypropylene/chemically modified attapulgite nanocomposites," Journal of Applied Polymer Science, vol. 121, no. 2, pp. 899-908, 2011.

[36] Q. G. Tang, F. Wang, M. R. Tang, and F. Q. Zhang, "Effect of attapulgite modification on properties of polypropylene nanocomposites," Applied Mechanics and Materials, vol. 320, pp. 407-412, 2013.

[37] J. Chen, Y. Yu, J. Chen, H. Li, J. Ji, and D. Liu, "Chemical modification of palygorskite with maleic anhydride modified polypropylene: Mechanical properties, morphology, and crystal structure of palygorskite/polypropylene nanocomposites," Applied Clay Science, vol. 115, pp. 230-237, 2015.

[38] S. M. G. Antonio, G. C. P. Iván, and G. R. J. Luis, "Influence of chemically treated palygorskite over the rheological behavior of polypropylene nanocomposites," Ingeniería, Investigación y Tecnología, vol. 16, no. 4, pp. 491-501, 2015.

[39] A. Li, A. Wang, and J. Chen, "Studies on poly(acrylic acid)/ attapulgite superabsorbent composite. I. Synthesis and characterization," Journal of Applied Polymer Science, vol. 92, no. 3, pp. 1596-1603, 2004.
[40] S. D. Ross and Q. Ketterings, "Recommended methods for determining soil cation exchange capacity," in Cooperative Bulletin No. 493.

[41] Y. Cai, J. Xue, and D. A. Polya, "A Fourier transform infrared spectroscopic study of Mg-rich, Mg-poor and acid leached palygorskites," Spectrochimica Acta - Part A: Molecular and Biomolecular Spectroscopy, vol. 66, no. 2, pp. 282-288, 2007.

[42] W. Yan, P. Yuan, M. Chen, L. Wang, and D. Liu, "Infrared spectroscopic evidence of a direct addition reaction between palygorskite and pyromellitic dianhydride," Applied Surface Science, vol. 265, pp. 585-590, 2013.

[43] S. Xue, M. Reinholdt, and T. J. Pinnavaia, "Palygorskite as an epoxy polymer reinforcement agent," Polymer, vol. 47, no. 10, pp. 3344-3350, 2006.

[44] A. Xue, S. Zhou, Y. Zhao, X. Lu, and P. Han, "Adsorption of reactive dyes from aqueous solution by silylated palygorskite," Applied Clay Science, vol. 48, no. 4, pp. 638-640, 2010.

[45] J. Madejová and P. Komadel, "Baseline studies of the clay minerals society source clays: infrared methods," Clays and Clay Minerals, vol. 49, no. 5, pp. 410-432, 2001.

[46] F. C. Liu, E. H. Han, W. Ke et al., "Polar influence of the organic modifiers on the structure of montmorillonite in epoxy nanocomposites," Journal of Materials Science and Technology, vol. 29, no. 11, pp. 1040-1046, 2013.

[47] L. A. Savas and S. Savas, "Interrelation between contact angle and interlayer spacing of montmorillonite clay used in polymer nanocomposites," Polymers and Polymer Composites, vol. 21, no. 3, pp. 129-132, 2013.

[48] Z. Zhang, J. Zhang, L. Liao, and Z. Xia, "Synergistic effect of cationic and anionic surfactants for the modification of $\mathrm{Ca}$ montmorillonite," Materials Research Bulletin, vol. 48, no. 5, pp. 1811-1816, 2013.

[49] Y. Hu, X. Liu, and Z. Xu, "Role of crystal structure in flotation separation of diaspore from kaolinite, pyrophyllite and illite," Minerals Engineering, vol. 16, no. 3, pp. 219-227, 2003.

[50] J. Ballah, M. Chamerois, S. Durand-Vidal, N. Malikova, P. Levitz, and L. J. Michot, "Effect of chemical and geometrical parameters influencing the wettability of smectite clay films," Colloids and Surfaces A: Physicochemical and Engineering Aspects, vol. 511, pp. 255-263, 2016.

[51] M. Hetzer and D. De Kee, "Wood/polymer/nanoclay composites, environmentally friendly sustainable technology: A review," Chemical Engineering Research and Design, vol. 86, no. 10, pp. 1083-1093, 2008.

[52] E. Manias, A. Touny, L. Wu, K. Strawhecker, B. Lu, and T. C. Chung, "Polypropylene/montmorillonite nanocomposites. Review of the synthetic routes and materials properties," Chemistry of Materials, vol. 13, no. 10, pp. 3516-3523, 2001.

[53] H. Baniasadi, A. Ramazani S.A., and S. Javan Nikkhah, "Investigation of in situ prepared polypropylene/clay nanocomposites properties and comparing to melt blending method," Materials and Design, vol. 31, no. 1, pp. 76-84, 2010.

[54] C. B. Hedley, G. Yuan, and B. K. G. Theng, "Thermal analysis of montmorillonites modified with quaternary phosphonium and ammonium surfactants," Applied Clay Science, vol. 35, no. 3-4, pp. 180-188, 2007.

[55] J. U. Calderon, B. Lennox, and M. R. Kamal, "Thermally stable phosphonium-montmorillonite organoclays," Applied Clay Science, vol. 40, no. 1-4, pp. 90-98, 2008. 
[56] L. Zhang, C. Wan, and Y. Zhang, "Investigation on the multiwalled carbon nanotubes reinforced polyamide 6/polypropylene composites," Polymer Engineering and Science, vol. 49, no. 10, pp. 1909-1917, 2009.

[57] L. N. Carli, J. S. Crespo, and R. S. Mauler, "PHBV nanocomposites based on organomodified montmorillonite and halloysite: the effect of clay type on the morphology and thermal and mechanical properties," Composites A: Applied Science and Manufacturing, vol. 42, no. 11, pp. 1601-1608, 2011.

[58] E. Bilotti, R. Zhang, H. Deng, F. Quero, H. R. Fischer, and T. Peijs, "Sepiolite needle-like clay for PA6 nanocomposites: an alternative to layered silicates?" Composites Science and Technology, vol. 69, no. 15-16, pp. 2587-2595, 2009. 

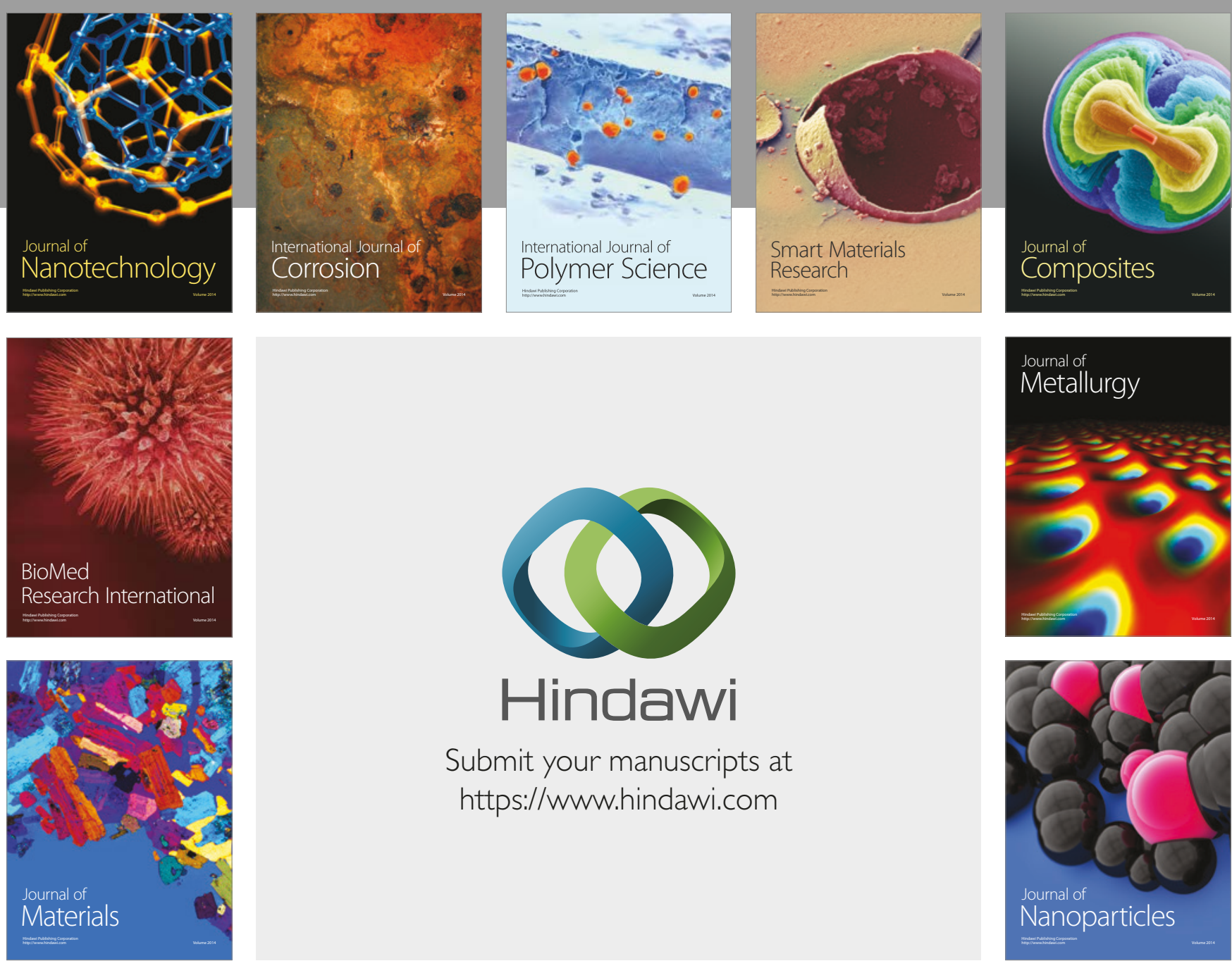

\section{Hindawi}

Submit your manuscripts at

https://www.hindawi.com
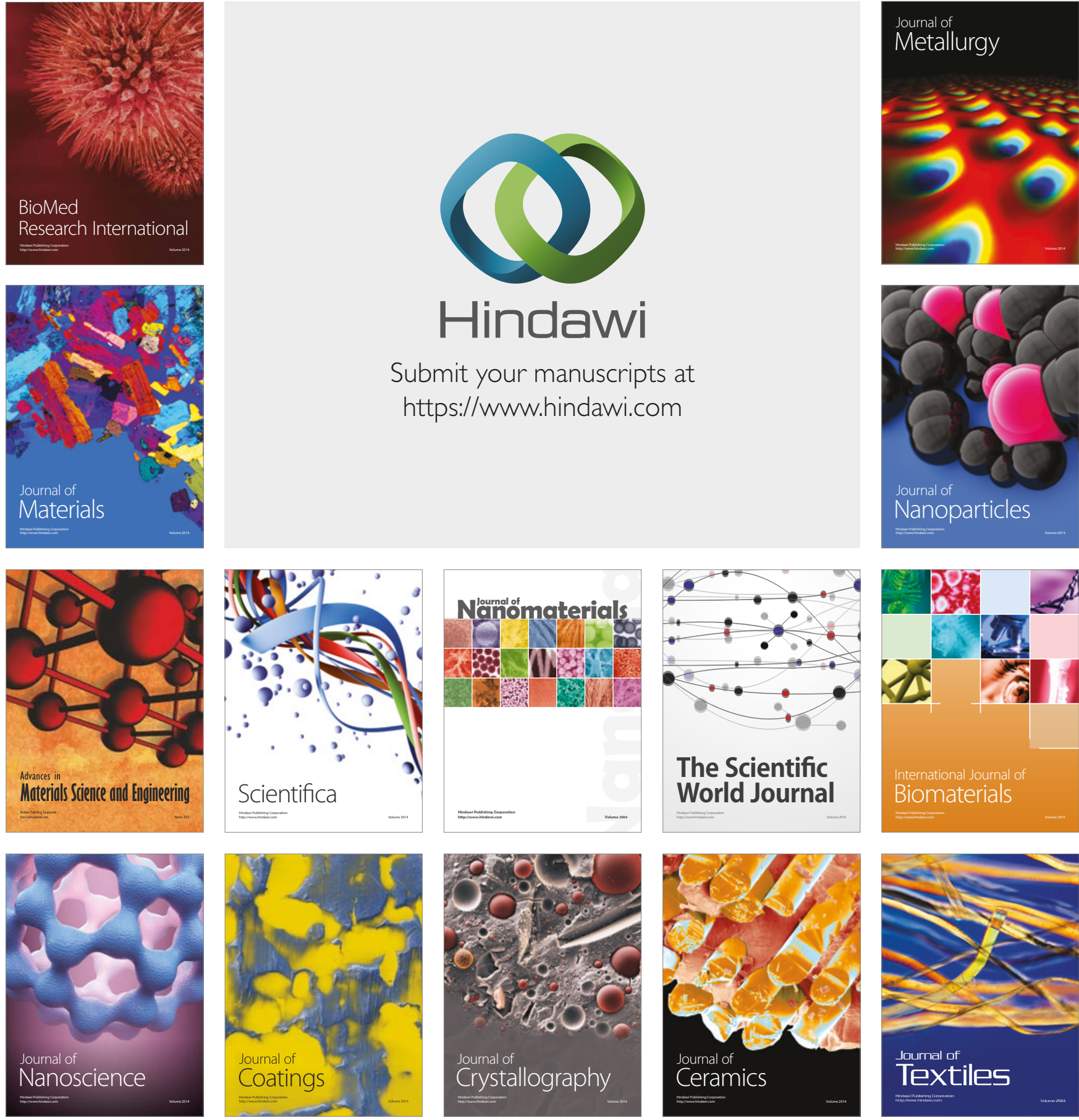

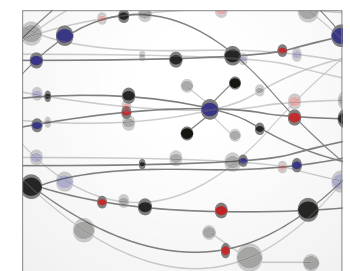

The Scientific World Journal
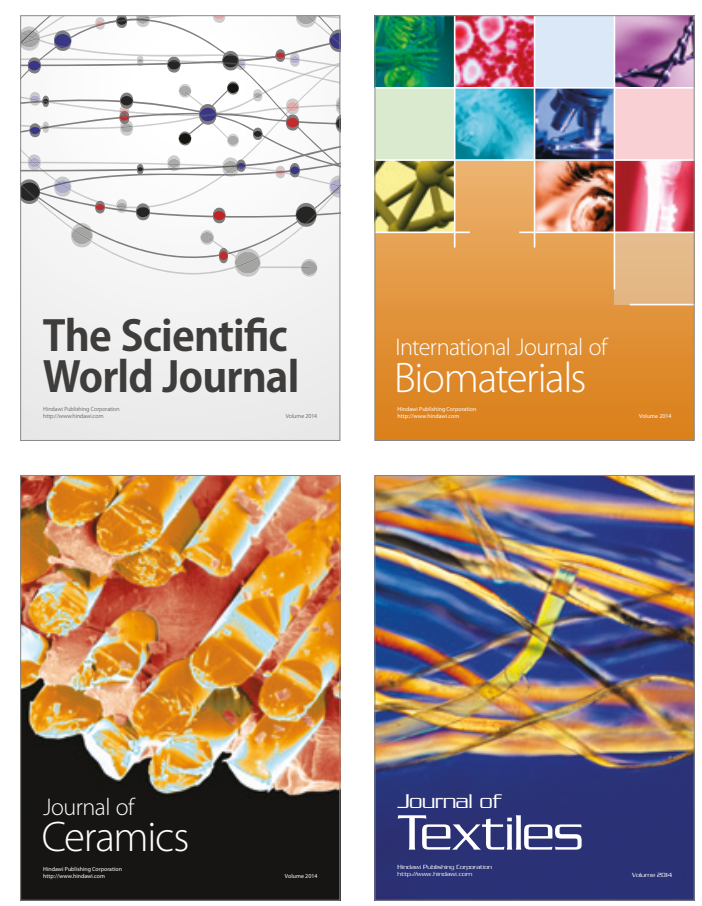